\title{
Committee planned to weigh misconduct in Australia
}

People who have no plans for conducting scientific studies will be the final arbiters of alleged breaches of research ethics when the Australian Research Integrity Committee is fully established in early 2011.

Expressions of interest in appointment to the committee, which closed in late May, required applicants to have knowledge of tribunal processes as well as legal or research governance experience, and no current or future involvement in research-related activities.

Individual research institutions currently bear responsibility for investigating alleged breaches of the national Code for the Responsible Conduct of Research, which was finalized in 2007.
The new integrity committee- - to be jointly administered by the Australian Research Council (ARC) and the National Health and Medical Research Council (NHMRC), Australia's top research funding agencies — will operate as an appeals tribunal for institutional decisions but will have no power to enforce its findings. It will appoint a panel of its members on a case-by-case basis to formally consider complaints of institutional misconduct and will report to the chief executive of the relevant funding body.

NHMRC Chief Executive Warwick Anderson and his ARC counterpart will retain the discretion to act on the new committee's findings. "The initial response would be to inform the university of the findings, offer advice on what should be done, and maybe hold them to account to abide by the code and report back to us," Anderson says.

Research institutions will retain ultimate responsibility for dealing with the committee's findings, a point underlined by Innovation Minister Kim Carr when he announced the committee's establishment on 12 April.

"While the committee will assess whether an institution has followed proper process in response to an allegation of research misconduct, it will not impinge on the institution's autonomy-institutions will still be responsible for assessing if misconduct has occurred," Carr said. Simon Grose, Canberra, Australia

\section{Lind guidelines offer a checklist for research priorities}

When it comes to medical treatment, the research community's agenda doesn't always match up with patients' desires. For instance, when people suffering from knee osteoarthritis were asked in 1999 what research was needed, they said they wanted more information on interventions such as braces, exercise regimens and pain management strategies. Yet most research at the time focused on drug and surgical treatments (Lancet 355, 2037-2040, 2000).

The Oxford-based James Lind Alliance was established in 2004 to help bridge such gaps. The nonprofit, funded by Britain's Department of Health and Medical Research Council, brings patients and clinicians together to identify top research priorities for a specific condition. On 11 May, the Alliance launched its online guidebook, intended to enable patients and clinicians to help set the medical research agenda (http://www. jlaguidebook.org/). The step-by-step manual explains how to establish partnerships among patient organizations and clinician groups, identify and prioritize unanswered questions in an area of science, and take the findings to funders.

"It strikes me as perverse that patients and clinicians aren't naturally the ones who determine priorities for medical research funding," says Lester Firkins, co-founder of the James Lind Alliance. "With the guidebook, we're giving people who want to try and set priorities an easy, structured way to do it."

"It's hard to imagine anyone in the world thinking this isn't a good idea," says Martin Burton, an ear, nose and throat (ENT) surgeon and president of the British Society for Academic Otolaryngology. The ENT community is forming a balance disorders partnership, the first of several disorders it plans to take on. "We're very interested in doing good, quality research for the benefit of patients, and the guidebook will be immensely helpful with that."

The do-it-yourself guide draws from the Alliance's experience working with patient and clinician organizations. In the past, for example, JLA helped walk the patient advocacy group Asthma UK and the research-oriented British Thoracic Society through the process of priority setting. Now, groups who want to form such partnerships without the JLA's direct assistance have the option of using the guidebook as they collaborate on priority setting. The guidebook, which took 18 months to write, includes questionnaire templates, draft agendas and case studies of different partnerships.

"Ideally, an uncertainty that wouldn't have come to light otherwise goes forward, is researched and makes a real difference to the patients and to the people who treat them," says Katherine Cowan, the guidebook author. "The guidebook is our online resource for how you do that."

"The guidebook is brilliant-I wish we'd had it a year and a half ago when we started the priority-setting process," says Emma Halls of the Prostate Cancer Research Foundation, which has gathered 163 research-oriented questions from clinicians and individuals with prostate cancer. Patients and clinicians will vote in September on the final ten questions, which will help guide the foundation's funding. The findings will also be entered in a national database to help direct future federally funded research. "As a charity completely funded by donors, it seemed really natural to ask clinicians and patients for their input. But it's really complicated," says Halls. "The James Lind Alliance has made it so much easier to manage the process."

Alisa Opar, New York
Correction
The article "Universal' immunizations get a boost in India' (Nat. Med. 16, 497, 2010), described the Indian Drugs and Pharmaceuticals Limited as "the largest vaccine producer of its kind." However, although the company is the country's largest public-sector producer of drugs and pharmaceuticals, it is not the largest vaccine producer. The text should have read " $\mathrm{A} 7.6$ billion rupee ( $\$ 170$ million) revival package was, as Nature Medicine went to press, still awaiting a cabinet nod to perk up the almost 50-year-old, government-owned Indian Drugs and Pharmaceuticals Limited (IDPL), the country's largest public sector producer of drugs and pharmaceuticals." The error has been corrected in the HTML and PDF versions of the article. 